\title{
PROPUESTAS DE RESISTENCIAS Y “RE-EXISTENCIAS" DESDE LA AMAZONÍA ECUATORIANA: El Caso del Pueblo Originario Kichwa de Sarayaku y las Luchas Antiextractivas ${ }^{1}$
}

\author{
http://dx.doi.org/10.21527/2176-6622.2020.54.44-55
}

Recebido em: 7/9/2020

Aceito em: 19/9/2020

\section{RESUMEN}

Juliane Rodrigues Teixeira

Doctorado en Estudios Americanos, Universidad de Santiago de Chile. Bolsista de doctorado - Agência Nacional de Investigação e Desenvolvimento (Anid) - Governo do Chile. Investigadora visitante do Centro de Estudos Sociais da Universidade de Coimbra, Portugal. http://lattes.cnpq.br/6299033315193253. juliane.rt@gmail.com

El artículo examina las acciones de resistencias y "re-existencias" propuestas desde la Amazonía ecuatoriana, destacando otras narrativas, epistemologías, ontologías y prácticas de algunos actores que luchan contra el modelo hegemónico extractivista y proponen alternativas, como los pueblos y nacionalidades indígenas de Ecuador. De esta forma, a través del examen al caso del Pueblo de Originario Kichwa de Sarayaku, ubicado en la Amazonía ecuatoriana y sus luchas de resistencia contra las transnacionales petroleras y el Estado ecuatoriano, y "re-existencias" por medio de propuestas como el Sumak Kawsay, el "buen vivir", y el Kawsak Sacha, la 'selva viviente', se evidencian las alternativas construidas a partir de otras racionalidades, asociadas a sus sistemas propios de vida. La metodología utilizada es de carácter cualitativo, a partir de la revisión bibliográfica de fuentes primarias y secundarias provenientes de diferentes ámbitos de las Ciencias Sociales.

Palabras-clave: Amazonía. Pueblo Originario Kichwa de Sarayaku. Resistencias. "Re-existencias". Luchas antiextractivistas.

PROPOSTAS DE RESISTÊNCIA E “RE-EXISTÊNCIAS” DA AMAZÔNIA EQUATORIANA:

O CASO DO POVO INDÍGENA KICHWA DE SARAYAKU E AS LUTAS ANTE EXTRATIVISTAS

\section{RESUMO}

O artigo examina algumas ações de resistência e "re-existências" provenientes da Amazônia equatoriana, destacando outras narrativas, epistemologias, ontologias e práticas de alguns atores que lutam contra o modelo extrativista hegemônico e propõem alternativas, como é o caso dos povos e nacionalidades indígenas de Equador. Desta forma, por meio da análise do caso do Povo Indígena Kichwa de Sarayaku, localizado na Amazônia equatoriana, abordam-se as suas lutas de resistência contra as empresas petrolíferas transnacionais e o Estado equatoriano e as propostas de "re-existência", como Sumak Kawsay, o "bem viver", e Kawsak Sacha, a "selva viva", construindo alternativas desde outras racionalidades associadas aos seus próprios sistemas de vida. A metodologia ocupada é de caráter qualitativa, com base na revisão bibliográfica de fontes primárias e secundárias de diferentes áreas das Ciências Sociais.

Palavras-chave: Amazônia. Povo Originário Kichwa de Sarayaku. Resistências. "Re-existências". Lutas antiextrativistas.

\section{SUMÁRIO}

1 Introducción. 2 Explotación del petróleo y el predominio del modelo extractivista en la amazonia ecuatoriana. 3 Las propuestas de resistencia: el caso sarayaku versus ecuador. 4 Las propuestas de "re-existencias": el sumak kawsay y el kawsak sacha. 5 Consideraciones finales. 6 Referencias.

\footnotetext{
1 Este artigo é producto de la tesis doctoral "La emergencia indígena y su incidencia en el pensamiento internacional latinoamericano: Un estudio de los casos de Ecuador y Bolivia en principios del siglo XXI".
} 


\section{INTRODUCCIÓN}

El artículo aborda las acciones de resistencias y "re-existencias" de pueblos y comunidades amazónicas, específicamente del Pueblo Originario Kichwa de Sarayaku, ubicado en la provincia de Pastaza, en la parte sur de la Amazonía ecuatoriana. Se resalta el caso emblemático de la lucha contra los consorcios transnacionales petroleros y el Estado ecuatoriano, buscando resistir y defender sus territorios, sistemas de vida ancestrales y cosmovisiones, así como las propuestas que emergen desde este mismo espacio, propuestas de "re-existencias" fundamentadas en los conceptos del Sumak Kawsay y Kawsak Sacha.

Precisamente, pensar desde la Amazonía permite insertar las voces de actores tradicionalmente silenciados en el mundo académico, posibilitando mirar la región desde una perspectiva poscolonial y decolonial que evidencia esta invisibilidad, pero que contribuye a inserir otras propuestas que trascienden el espacio académico, incidiendo en los debates políticos, en textos constitucionales y en la formación de políticas públicas que pueden ser alternativas a algunos problemas actuales.

Se destaca que, tradicionalmente, el poblamiento y el desarrollo de la región amazónica ha estado condicionado por el paradigma eurocéntrico y racionalista que fundamenta las relaciones duales entre la sociedad y naturaleza, apoyado en un modelo de crecimiento económico lineal e infinito sostenido por de la explotación constante de los recursos naturales, considerados como recursos inagotables. Por ende, se torna cada vez más importante modificar estos patrones de desarrollo mediante el uso racional de las riquezas naturales y de los saberes ancestrales de las poblaciones que habitan la Amazonía, tomando en cuenta los conocimientos acumulados a lo largo del tiempo, atribuyendo importancia a sus habitantes.

Justamente, la región amazónica se caracteriza por presentar varias dicotomías y disputas. Es un espacio en que se desarrollan distintos proyectos geopolíticos. Entre estas dinámicas se sobresalen la existencia de movimientos de oposición a la apropiación irracional de los recursos naturales llevados a cabo por diversos actores, como es el caso de los pueblos indígenas, que históricamente han luchado por sus derechos y han propuesto alternativas al modelo de desarrollo dominante.

En efecto, la región puede ser considerada como un espacio de encuentros y desencuentros en que se acentúan elementos como la diversidad humana, civilizacional, ambiental, epistemológica y ontológica, además de su rol estratégico para enfrentar la actual crisis ambiental global. Así, es un espacio de encuentro entre intereses globales y locales que traen consigo distintos saberes que disputan su significado junto a la presencia de dicotomías como explotación, protección; desarrollo, preservación; modernidad y ancestralidad.

Se considera importante abordar los conflictos que ocurren en países amazónicos, como es el caso de Ecuador, dado que es tanto un país amazónico, ya que la Amazonía representa casi $50 \%$ de su superficie geográfica, como un país petrolero que depende fundamentalmente de la extracción de este recurso para su economía, en que gran parte de las reservas se encuentran justamente en la región amazónica, lo que torna más complejo las dinámicas llevadas a cabo en la región. La situación se complica aún más en la medida en que se ha transformado en un Estado plurinacional, a partir de la Constitución de 2008, atribuyendo una mayor autonomía a los pueblos y nacionalidades indígenas del país, como es el caso del Pueblo Originario de Sarayaku.

Así, se tornan relevantes los múltiples actos de oposición de las comunidades ancestrales, como son las luchas contra la actuación de las transnacionales petroleras en función de la expansión neocolonial intensificada por el sistema neoliberal contemporáneo, como el caso de las luchas llevadas a cabo por el Pueblo Originario Kichwa de Sarayaku, buscando preservar sus sistemas ancestrales de vida.

Además de la resistencia, proponen "re-existencias". La expresión "re-existencia" está asociada con las propuestas de Catherine Walsh (2017), quien resalta los mecanismos y prácticas que contribuyen con la "re-significación" y la "re-definición" de aspectos básicos, apoyados en la "auto-determinación". Están vinculadas con las acciones sociales, políticas y epistémicas que buscan romper con los postulados hegemónicos desde una perspectiva decolonial. La autora resalta las insurgencias, resistencias y "re-existencias" de diversos pueblos en contra del despojo, la desterritorialización y las lógicas del sistema global de acumulación del capital. Asocia la "re-existencia" desde diversos ámbitos, como física, simbólica, social, cultural, espiritual y cognitiva, precisamente lo que el caso del Pueblo Originario de Sarayaku proporciona. 
La metodología ocupada es de carácter cualitativo, a partir de la revisión bibliográfica de fuentes primarias y secundarias, como documentos, artículos científicos, libros y tesis de posgrado que tratan del tema, provenientes de diferentes ámbitos del conocimiento, como Sociología, Estudios del Desarrollo, Derecho y Derecho Internacional. Se resalta el uso de documentos y artículos académicos elaborados por algunos de los propios miembros de la comunidad.

El trabajo está divido en tres partes. Primeramente, se aborda la explotación del petróleo y el predominio del modelo extractivista en la Amazonía ecuatoriana, resaltando las contradicciones y los problemas enfrentados por este modelo de desarrollo. En seguida, se abordan las propuestas de resistencias, vinculadas con la demanda del Pueblo Originario Kichwa de Sarayaku contra el Estado ecuatoriano, y por fin, las propuestas de "re-existencias", abordando conceptos como el Sumak Kawsay y el Kawsak Sacha.

\section{EXPLOTACIÓN DEL PETRÓLEO Y EL PREDOMINIO DEL MODELO EXTRACTIVISTA EN LA AMAZONIA ECUATORIANA}

La economía ecuatoriana depende fundamentalmente de la extracción del petróleo, en que gran parte de las reservas se encuentran en la región amazónica, región con gran diversidad socioambiental y cultural. Los ingresos petroleros han representado casi la mitad de la recaudación estatal, estando el proceso de desarrollo nacional fuertemente asociado a la volatilidad de los precios de la commodities a nivel internacional.

Luego, se considera que el desarrollo económico ecuatoriano está fundamentado en el extractivismo como un modo particular de extracción y explotación de los recursos naturales, como las extracciones mineras y petroleras. Generaron altos niveles de contaminación, deforestación e impactos sobre la biodiversidad y las formas de vida de las poblaciones locales al privilegiar las actividades económicas direccionadas a la exportación (GUDYNAS, 2015). Están inseridas en las lógicas del mercado global que requieren la aceleración del ritmo de la producción o explotación de los recursos, sin tomar en cuenta las consecuencias socioambientales y culturales de este proceso, llevando al agotamiento de los recursos e incluso al agotamiento de las capacidades de readaptación de la naturaleza, dado la forma irracional de la producción del sistema capitalista contemporáneo (BAUTISTA, 2019).

El caso del petróleo en Ecuador, así como ocurre en otros países de nuestra región, evidencia la "paradoja de la abundancia", dado que la riqueza de recursos naturales no se transforma en desarrollo del bienestar de la ampla mayoría población, sino que distorsiona la estructura a partir de la asignación desigual de los recursos económicos obtenidos con los procesos extractivistas, concentrando la mayoría de los beneficios económicos en los sectores que detienen mayor poder, o incluso siendo transferidos a otros países, generalmente países del centro del sistema internacional. De este modo, los países extractivistas, cuyas economías se han desarrollado primordialmente a partir de la extracción y explotación de los recursos naturales difícilmente han logrado avanzar en el desarrollo económico y social de la mayoría de la población (BERRÍOS; CUEVAS, 2014).

En este sentido, Alberto Acosta (2011) hace referencia a la "paradoja de la abundancia" y a las experiencias históricas y las evidencias recientes que señalan el vínculo entre la pobreza de diversos países y la abundancia en recursos naturales, ya que la mayoría de los países ricos en recursos naturales sustentan sus modelos económicos en la extracción y exportación, generando problemas asociados a la dependencia de estos recursos para financiar sus modelos de desarrollo interno.

De acuerdo con el referido autor, el extractivismo puede ser considerado como un mecanismo de apropiación de los recursos naturales de carácter colonial y neocolonial, adquiriendo diversas formas a lo largo del tiempo al adaptarse a las exigencias de materias primas necesarias para el desarrollo industrial y el bienestar social del Norte Global, asociado con cada período histórico, generando pocos beneficios en las naciones extractivas. Ha sido una constante en la política, económica y social a lo largo de la historia de los países del Sur Global, con distintos grados de intensidad. Así, en América Latina, la dependencia durante el período colonial, a través de la extracción y exportación de materias primas se ha mantenido a lo largo de la historia, con otros matices (ACOSTA, 2011).

Pese que las actividades extractivistas poseen una historia que remonta a los tiempos coloniales, ha adquirido cada vez mayor relevancia en las últimas décadas, convirtiéndose en un elemento importante que incide en la reestructuración territorial, generando impactos ambientales a gran escala, así como efectos eco- 
nómicos, políticos, sociales y culturales amplios, como es el caso de los conflictos en la Amazonía. Es un fenómeno que ocupa un papel central en las dinámicas políticas, económicas, sociales y culturales del continente (GUDYNAS, 2015).

Según el Pueblo Originario de Sarayaku (2009), los antecedentes de la actividad petrolera en la región, que remontan a principios del siglo 20 , incidieron en los procesos de desarrollo y ocupación del territorio amazónico, definiendo las políticas públicas aplicadas para resguardar los intereses de las petroleras por encima de los derechos de los pueblos amazónicos. Luego, resaltan como la existencia de recursos petrolíferos ha condicionado y afectado gravemente el modo de vida de poblaciones ancestrales, llevando a la injerencia de poderes externos que buscan dominar la región.

Agregan que el boom petrolero corresponde al período de 1971 hasta 1981, momento en que la renta proveniente de la explotación del petróleo creció en la economía nacional, ampliando la exportación de petróleo y la dependencia hacia al producto. No obstante, resaltan las consecuencias negativas, como el aumento de la deuda externa y la injerencia de instituciones financieras internacionales en el país. De este modo, la actividad petrolera ha sido la principal fuente económica del país durante un largo período junto al crecimiento de la deuda externa, respaldado justamente por los ingresos del petróleo, problema que sigue hasta la actualidad (PUEBLO..., 2009).

En efecto, las consecuencias de las actividades extractivas en ecosistemas más frágiles, como es el caso de la Amazonía, inciden en las poblaciones que tradicionalmente han tenido modelos y sistemas de vida armónicos y en equilibrio con la naturaleza, siendo estas relaciones alteradas a partir del ingreso de las empresas extractivistas a sus territorios, estimulando la acción colectiva de resistencia de estos grupos, generando conflictos socioambientales que requieren, además de analizar los daños ambientales causados, examinar las violaciones a los derechos humanos y a los derechos colectivos de estos grupos (ARCOS HERVA, 2016).

Justamente, el Pueblo Originario de Sarayaku (2009) resalta los altos costos socioambientales vinculados al boom petrolero, especialmente los impactos negativos en la parte norte de la región amazónica, local donde se ha extraído mayor cantidad de petróleo: Texaco ${ }^{2}$ como la transnacional protagonista del boom petrolero en el país, operando en la región amazónica desde 1964 hasta 1990, contaminó el territorio, las aguas y el aire de la región, transformando el boom petrolero en un posterior desastre socioambiental y cultural, vinculado con las inversiones mínimas en la búsqueda de mayores ganancias, sin tomar en cuenta los impactos ambientales y sociales generados a lo largo del período de explotación, siendo Petroecuador empresa que sigue con la operación, manteniendo la contaminación en la región.

Eduardo Gudynas (2015) resalta el notable aumento de las actividades extractivistas contemporáneamente en América Latina, apoyado en los altos precios de las materias primas en principios del siglo 21, junto al aumento de la demanda internacional, especialmente debido al ascenso de China en la economía global. ${ }^{3}$ Sin embargo, los cambios generados por los gobiernos progresistas ${ }^{4}$ en las actividades extractivas en las últimas décadas en la región no han logrado ser direccionados hacia la superación de la modalidad de acumulación y desarrollo económico extractivista. Siguen sustentados en la importancia de los sectores extractivistas como elemento central de sus modelos de desarrollo, generando nuevos modelos de extractivismos que mantienen la estructura de acumulación hegemónica (ACOSTA, 2011).

\footnotetext{
Es importante destacar el juicio en contra de la compañía por parte de pueblos y nacionalidades indígenas y campesinos del Ecuador. Además de los daños ambientales, sociales y culturales a las comunidades, pueblos y nacionalidades ancestrales de la zona, como los Cofán, Kichwa, Secoya y Waorani, se destaca también la extinción de los pueblos ancestrales Tetete y Sansahuari. El juicio evidenció los problemas técnicos de la empresa al ocupar la tecnología a bajo costo para maximizar sus lucros, sin la preocupación por las consecuencias socioambientales generadas por la explotación del petróleo, ocupando métodos prohibidos por ley en Estados Unidos (ACOSTA, 2015).

No obstante, la llegada al fin del período de crecimiento económico en 2014 se da precisamente por la caída de los precios de las commodities, como reflejo de los cambios en la estrategia de desarrollo interno de China, que pasó a priorizar la expansión de su mercado interno, afectando América Latina (LARREA MALDONADO; BRAVO; SAÉNZ, 2017).

${ }^{4}$ En el caso ecuatoriano, Larrea Maldonado, Bravo e Saénz (2017) resalta las políticas ambientales de carácter progresista que predominaron en los primeros años del gobierno de Rafael Correa, como el reconocimiento constitucional de los derechos de la naturaleza y la Iniciativa Yasuní ITT, propuesta en 2007, que proponía la preservación del área de explotación de petróleo a cambio de la instauración de un fondo internacional. No obstante, apunta a los cambios a partir de 2009, momento en que el gobierno pasó a ejecutar una estrategia de carácter extractivista, cancelando la Iniciativa Yasuní ITT en 2013, iniciando su explotación en 2016, sin tomar en cuenta la caída en el precio del petróleo en el mercado internacional. Resalta la extracción petrolera en nuevos campos, y el fuerte impacto ambiental, junto al bajo uso de tecnología con menores impactos en la explotación petrolera en el país.
} 
De este modo, Acosta (2011) resalta el neoextractivismo. Señala que mantiene las formas de inserción internacional subordinada y funcional a la globalización hegemónica, beneficiando al capitalismo transnacional a costas de los impactos sociales y ambientales generados por la intensificación de las actividades extractivitas. No obstante, apunta a algunos cambios importantes, como el incremento de la presencia y del papel activo del Estado en la actividad, a través de acciones directas de las empresas estatales, o indirectas, evidenciando una postura nacionalista que atribuye mayor importancia al acceso y control de los recursos naturales por parte del Estado, así como sobre los beneficios financieros originados por la extracción de estos recursos, llevado a una mejor redistribución de la renta petrolera en el país.

Considera que la postura de carácter nacionalista de los gobiernos progresistas cuestiona el control de los recursos naturales por parte de las transnacionales, buscando beneficios económicos que puedan ser redistribuidos entre toda la colectividad nacional, a través de la capitación de una mayor parte del excedente proveniente del sector. Entretanto, no problematiza la extracción, ni los problemas socioambientales y culturales generados en los territorios en que estas actividades son llevadas a cabo. Estos gobiernos utilizan estos recursos en los programas sociales, lo que legítima la manutención de las actividades de explotación, tornándose cada vez más indispensables para lograr combatir la pobreza y alcanzar el desarrollo de la región (ACOSTA, 2011).

En este mismo sentido, el intelectual boliviano Rafael Bautista (2019) considera que las acciones de los gobiernos progresistas pueden haber sido antineoliberales, pero siguieron sosteniendo el capitalismo en su modelo hegemónico, especialmente a partir de los ideales de la modernidad eurocéntrica, como es el progreso infinito, base epistémica de la racionalidad moderna que hoy está en crisis, teniendo en cuenta que la naturaleza, como proveedora de recursos naturales, no es infinita.

Carlos Larrea Maldonado (LARREA MALDONADO; BRAVO; SAÉNZ, 2017), asesor técnico de la Iniciativa Yasuní ITT ${ }^{5}$, resalta el boom económico vivenciado en Ecuador durante el período de 2004 hasta 2014, llevando al crecimiento económico y a la mejoría de la calidad de vida en el país. Pero, debido a la vulnerabilidad económica y social, la caída de los precios de las commodities en el mercado internacional ha llevado a la crisis, dado la baja diversificación económica y productiva llevada a cabo durante el período del boom económico.

De este modo, pese los logros y avances conquistados durante este período, el país no ha logrado superar los obstáculos de lo que denomina la "maldición de la abundancia", lo que explica como los límites estructurales que son obstáculos para que los países cuyo desarrollo depende de la exportación de recursos primarios, como es el caso del petróleo y los minerales, de lograr un crecimiento económico estable a lo largo del tiempo ${ }^{6}$, logrando también diversificar su producción (LARREA MALDONADO; BRAVO; SAÉNZ, 2017).

Sobre la concepción de la naturaleza proveedora de recursos de modo infinito, el referido autor advierte sobre la disminución de la capacidad de extracción de petróleo en los campos petrolíferos más antiguos del país, así como el aumento de la demanda interna por el producto, lo que disminuyó la exportación de petróleo en los últimos años. Considera que las extracciones futuras de petróleo son restringidas en Ecuador, dado que las estimativas de reservas petroleras permiten la explotación continúa de petróleo por solamente 20 años, lo que lleva a la posterior dependencia de la descubierta de otros yacimientos, así como los problemas

\footnotetext{
La Iniciativa Yasuní ITT fue un proyecto que buscó garantizar la protección de la Amazonía y de sus comunidades, propuesto por Rafael Correa en 2007, comprometiéndose a no explotar las reservas de petróleo ubicadas en el Parque Nacional Yasuní, en la Amazonía ecuatoriana, a cambio de la colaboración de la comunidad internacional a través de la compensación de $50 \%$ de los recursos que el país recibiría por la explotación del petróleo en esta zona, contribuyendo a la mitigación de cambio climático al no emitir gases efecto invernadero, tampoco explotar la parte del ecosistema vulnerable. Entretanto, fracasa, dado la falta de recursos obtenidos, llevando a la posterior explotación petrolera en la región (BERRÍOS; CUEVAS, 2014). Hidalgo-Capitán y Cubillo Guevara (2019) consideran que las acciones de resistencias, buscando la manutención del petróleo bajo tierra por parte de la comunidad de Sarayaku fue una influencia para iniciativa Yasuní ITT.

6 Según Carlos Larrea Maldonado, Bravo e Saénz (2017), a lo largo de 45 años, el desempeño económico del país ha sido de carácter tanto débil, como inestable, frente a las constantes fases de expansión y crisis. Resalta los períodos de crecimiento económico del país asociados al boom petrolero de 1972 hasta 1982, y del período neoextractivista de 2004 hasta 2014. Estas fases fueron seguidas por períodos largos de estancamiento económico y ajustes neoliberales, como el período entre 1982 y 2004, así como el período actual, asociado a una nueva baja en los precios de las commodities en el mercado internacional desde 2014.
} 
asociados a la minería, dado la baja rentabilidad de las reservas de cobre y oro que se estima que existan, evidenciando cada vez más la inestabilidad e insostenibilidad de mantener el desarrollo del país fundamentado en el modelo extractivista (LARREA MALDONADO; BRAVO; SAÉNZ, 2017).

Además, señala los altos costos ambientales de las actividades extractivitas en los países periféricos, así como los conflictos socioambientales en estos territorios, planteando la importancia de buscar alternativas a partir de otros paradigmas alternativos al desarrollo. Considera necesario pensar el desarrollo asociado a la efectiva mejoría en la calidad de vida de la mayor parte de la población, respetando los límites de los ecosistemas naturales y la diversidad social y cultural existente a través de alternativas económicas que llevan a la equidad al mismo tiempo en que mantengan la sustentabilidad. En este sentido, resalta la biodiversidad única presente en el país, así como la diversidad cultural, asociadas al buen vivir, que pueden servir de alternativas económicas, pero que son desperdiciadas por los gobiernos de turno (LARREA MALDONADO; BRAVO; SAÉNZ, 2017).

En este mismo debate, Gudynas (2015) menciona las dimensiones del extractivismo, la local, asociada a territorios específicos, en que se generan las externalidades, y la apropiación de estos recursos por el mercado global. Asocia el extractivismo a las resistencias a los emprendimientos en territorios particulares, como es el caso de la Amazonía, vinculado con las movilizaciones ciudadanas que se intensifican contemporáneamente.

Por consiguiente, el mismo Pueblo Originario de Sarayaku (2009) destaca las resistencias indígenas frente los ingresos de las industrias extractivistas en su territorio buscando frenar la expansión de la frontera extractivista en la Amazonía ecuatoriana. Los conflictos empiezan en la década de 1980 en la región, ampliando la participación política de las organizaciones indígenas de la Amazonía.

\section{LAS PROPUESTAS DE RESISTENCIA: EL CASO SARAYAKU VERSUS ECUADOR}

El caso del Pueblo Originario Kichwa de Sarayaku puede ser considerado como un caso emblemático de una comunidad contra las políticas públicas que benefician a las grandes transnacionales, por encima de los derechos humanos y colectivos de los pueblos ancestrales que han tenido sus territorios intervenidos por estas empresas. Resalta la importancia de la comunidad y su resistencia a la actividad petrolera durante décadas, promoviendo una campaña internacional en contra de la explotación petrolera en la Amazonía ecuatoriana, rechazando las ofertas económicas y los diálogos con las compañías, consolidando la resistencia a las actividades extractivistas.

De acuerdo con documentos de la propia comunidad presentados en la Corte Interamericana de Derechos Humanos durante la demanda contra el Estado de Ecuador, el problema se intensifica con la concesión petrolera del Estado a la Compañía General de Combustibles (CGC), de Argentina, sobre el Bloque 23 que comprende parte del territorio del pueblo de Sarayaku, en 1996. Este hecho ocurrió sin la debida participación de la comunidad a través de la consulta y el consentimiento previo, libre e informado y sin la realización de estudios de impactos sociales y ambientales necesarios. De esta forma, destacan el rechazo del Pueblo de Sarayaku a la petrolera que no fue tomado en cuenta por el Estado. La entrada de la compañía al territorio ancestral con el apoyo estatal generó impactos en la biodiversidad y deforestación del territorio, incidiendo en la manutención del modo de vida comunitario, evidenciando las vulneraciones de los derechos colectivos de los pueblos indígenas por parte del propio Estado ecuatoriano (PUEBLO..., 2009).

En 2002, tienen inicio las incursiones de la empresa petrolera al territorio de Sarayaku, sin tomar en cuenta la prohibición votada en la Asamblea de la comunidad, lo que ha llevado al pueblo de Sarayaku a tomar medidas legales en las instancias nacionales desde este entonces, logrando decisiones judiciales que suspendían las actividades del bloque. Entretanto, la empresa violó dichas prohibiciones al seguir con los trabajos en territorio ancestral (MELO, 2004). Las demandas buscaban la garantía de la integridad de su territorio, así como la integridad física de sus habitantes y el derecho a la libre circulación y ejercicio de la autonomía junto a la manutención de su sistema propio de vida (ARCOS HERVA, 2016).

La estrategia legal llevada a cabo por la comunidad, juntamente con la estrategia de incidencia política, ha logrado ampliar el espacio de visibilidad del caso en el ámbito nacional e internacional, incrementando la capacidad de resistencia frente al Estado y la petrolera, culminando con la demanda en el ámbito del Sistema Interamericano de Derechos Humanos luego que la justicia interna fuera incapaz de garantizar la preservación de los derechos humanos y colectivos de la comunidad. El caso fue elevado al ámbito internacional a partir 
de 2003, logrando la concesión de medidas cautelares por parte de la Comisión Interamericana de Derechos Humanos, la $\mathrm{CIDH}$, luego reafirmadas por la Corte Interamericana de Derechos Humanos, y la posterior desistencia de la transnacional petrolera en seguir con las actividades extractivas (MELO, 2004).

La ampliación del conflicto entre el consorcio petrolero y la comunidad ocurre cuando se realizaron trabajos en la zona, tallando arboles considerados sagrados para la comunidad, sin consultarla. Esto fue visto como una agresión a la comunidad y su sistema de vida (HIDALGO-CAPITÁN; CUBILLO-GUEVARA, 2019). Además, la propia comunidad destaca el abandono de explosivos utilizados para la explotación sísmica, generando problemas ambientales y sociales que impiden el libre uso del territorio por parte de la comunidad, evidenciando un peligro para la salud y la vida de sus habitantes, afectando a zonas de caza, pesca y zonas sagradas y áreas con plantas medicinales esenciales para mantener el bienestar de la población. Esto ha incidido directamente también en la cultura y la espiritualidad del pueblo, afectando la cosmovisión y el sistema de vida comunitario (PUEBLO..., 2009). Hasta la fecha, los explosivos se mantienen enterrados en el territorio de Sarayaku, evidenciando una medida que no fue totalmente cumplida por parte del Estado ecuatoriano, establecida en la sentencia emitida por la Corte Interamericana de Derechos Humanos (CARCELÉN, 2017).

La comunidad señala la concesión de medidas de protección por parte de la CIDH, reafirmadas por la Corte, concluyendo que existían violaciones cometidas en contra del pueblo de Sarayaku por parte del Estado. En 2003, la CIDH solicitó al Estado ecuatoriano adoptar medidas cautelares de protección a la integridad física y a la vida de sus integrantes, especialmente de los líderes de la comunidad, además de proteger el territorio a favor del pueblo de Sarayaku (PUEBLO..., 2009). Entretanto, los intereses prioritarios del gobierno estaban asociados con la ampliación de la frontera petrolera, minimizando la defensa de los derechos humanos y colectivos de la comunidad (MELO, 2004).

La sentencia fue emitida por la Corte, en 2012, a favor de la comunidad de Sarayaku, considerando que el Estado atentó en contra del derecho a la consulta de la comunidad, así como atentó en contra del derecho a la propiedad comunitaria indígena, y a los derechos de la vida, integridad y libertad personal de sus habitantes, culminando con la falta de garantías y protección judicial al pueblo de Sarayaku. La comunidad logró evidenciar la responsabilidad internacional de Ecuador por violaciones a sus derechos humanos y colectivos (ARCOS HERVA, 2016).

Luego, el caso de Sarayaku expone las debilidades en las políticas públicas de derechos humanos y colectivos de países dependientes de la explotación de recursos naturales, privilegiando los intereses de las industrias extractivas y las ganancias generadas por estas para financiar sus economías, pese la violación a los derechos humanos de una parte de la población. Así, este caso permite reflexionar sobre las estrategias de desarrollo económico adoptadas por los Estados sin la debida preocupación por las consecuencias socioambientales y culturales en los territorios donde las actividades extractivistas son llevadas a cabo, incidiendo negativamente en los sistemas de vida de las comunidades (MELO, 2004).

Al mismo tiempo, el caso evidencia la capacidad de organización del Pueblo Originario de Sarayaku y sus acciones de resistencia frente a las actividades extractivistas en su territorio. Son acciones que transcienden el espacio nacional al llegar a las instancias internacionales buscando resguardar su territorio de acuerdo con sus concepciones propias de vida y de mundo, construyendo formas de "re-existencias".

\section{LAS PROPUESTAS DE “RE-EXISTENCIAS”: El Sumak Kawsay y el Kawsak Sacha}

El Pueblo Originario de Sarayaku (2009) destaca la importancia del contacto con la naturaleza y la constante búsqueda por preservar sus tradiciones y regenerar la flora y fauna de la región. Su cosmovisión está apoyada en el Kawsak Sacha, es decir, en la 'selva viviente', el espacio en donde se producen emociones sicológicas, físicas, espirituales y la vida, como elemento esencial de sus cosmovisiones. Para sus habitantes, la selva y todo lo que se encuentra en el territorio poseen vida y dimensión espiritual, así la tierra y la selva son proveedores de energía y de vida.

De esta manera, se resalta la dimensión espiritual sagrada del territorio que está presente en su cosmovisión, en que el mundo animal se encuentra protegido por los espíritus superiores. Engloba a todos los elementos, como ríos, montañas y la tierra como espacios donde habitan los espíritus considerados fuentes de vida, de conocimiento y de identidad. Por ende, dentro del Kawsak Sacha, todo está entrelazado, actuando 
en reciprocidad y complementariedad a través de una red que conecta a todos los seres vivientes presentes en la selva, razón por la cual apuntan a la preservación de la vida en todos los sentidos, dado que todo posee energía y vida, como los seres humanos (PUEBLO..., 2009).

Franco Viteri (2004), uno de los líderes del Pueblo Originario de Sarayaku, destaca las formas de resistencias desde los ámbitos políticos y jurídicos, en que se encuentra presente la connotación espiritual de las luchas, asociada a la cosmovisión del pueblo que apunta a la naturaleza como la base fundamental del sistema de vida comunitario. Así, enfatiza las dimensiones de las luchas y las resistencias de Sarayaku, contribuyendo a la construcción del Estado plurinacional ${ }^{7}$ a través de otras formas de construcción del orden económico, apoyadas en la justicia social, y en los derechos económicos, políticos, sociales y culturales propios de los pueblos indígenas, asociadas a las históricas demandas de autodeterminación de los pueblos y nacionalidades indígenas del país.

José Gualinga (2017), otro de los líderes del Pueblo Originario de Sarayaku, resalta la importancia del Kawsak Sacha, la 'selva viviente', para lograr el Sumak Kawsay. Floresmilo Simbaña (2011), uno de los líderes del movimiento indígena ecuatoriano considera que el Sumak Kawsay es un concepto que está generando diversos debates en los ámbitos políticos y académicos al formar parte de la estructura normativa de las Constituciones de Ecuador y Bolivia ${ }^{8}$ y ser un elemento importante en los discursos del movimiento indígena frente al neoliberalismo. Está asociado a la memoria histórica de los pueblos originarios. ${ }^{9}$

Considera que el Sumak Kawsay forma parte de un sentido de vida que ha estado presente en la memoria larga de las comunidades indígenas de la región andina y amazónica como un modelo ético que organiza la vida en comunidad, precisamente el sistema de vida andino y amazónico. Antes de la colonización europea, este sentido de vida auxiliaba en la organización de las comunidades. El Sumak Kawsay ha sido rescatado después de siglos de intervención colonial, volviendo a ser practicado por las comunidades (SIMBAÑA, 2011).

Los pilares del Sumak Kawsay expuestos por el Pueblo Originario de Sarayaku, para la construcción del propio buen vivir hacen hincapié en los rechazos a las actividades petroleras en su territorio; plantea la autodeterminación; la implementación de un modelo económico propio en equilibrio con la selva amazónica; el desarrollo de sus propios conocimientos, salud propia y energías alternativas; busca contribuir a la construcción del Estado plurinacional y democrático en el país. El concepto también es ocupado por otros sectores del movimiento indígena en sus reivindicaciones (CRESPO, 2017).

Vale la pena también mencionar las tensiones entre la concepción del Sumak kawsay, inicialmente propuesta por el movimiento indígena ecuatoriano y la posterior traducción al 'buen vivir' y la incorporación al proyecto de desarrollo del gobierno de Rafael Correa, simbolizando un concepto en disputa. En este sentido, se observan las dificultades de traducir conceptos que no encuentran correspondencia exacta en otros idiomas, lo que puede tornar sus significados más amplios. Esto es precisamente lo que sucedió con las traducciones del Sumak Kawsay y Suma Qamaña para el "buen vivir", presente en la Constitución de Ecuador, y el 'vivir bien', presente en la Constitución de Bolivia (LLASAG, 2017).

De esta manera, el Sumak Kawsay de los pueblos amazónicos, asociado a la cosmovisión indígena, animista y holística, señala la importancia de la selva que abarca los habitantes, tanto humanos, como no humanos, que deben mantenerse en relación de armonía. Desde esta visión, los seres humanos no son considerados seres superiores a la naturaleza, por lo tanto, no poseen el derecho de apropiarse de ella. En el contexto actual, puede expresarse en las acciones que buscan recuperar la identidad y resaltar las formas de resistencia de los pueblos indígenas, especialmente frente al despojo de sus territorios (LARREA MALDONADO; BRAVO; SAÉNZ, 2017).

\footnotetext{
7 La plurinacionalidad transforma la institucionalidad tradicional del Estado-nación moderno eurocéntrico, confiriendo una mayor autonomía y derechos colectivos a los pueblos y nacionalidades indígenas sobre sus territorios. Así, puede ser considerado un modelo contemporáneo de organización política que surge en América Latina, reconociendo la autonomía de los pueblos y nacionalidades indígenas, al mismo tiempo en que contribuye al proceso de emancipación de estos grupos tradicionalmente excluidos de los espacios políticos durante siglos en la región, estando asociados con sus luchas históricas (BERNAL-MEZA, 2016).

8 En el caso de Ecuador, la Constitución de 2008 reconoce la interculturalidad, la plurinacionalidad y la naturaleza como sujeto de derechos, representando un logro para las nacionalidades y pueblos indígenas del país, además de apuntar a posibilidades de cambios paradigmáticos a partir de la introducción de conceptos filosóficos kichwas, como es el caso del Sumak Kawsay, el 'buen vivir' (CASTRO MUNIZ; CÁRDENAS PIEDRAHÍTA, 2018).

9 Carmen Seco Pérez (2017) considera que cada pueblo indígena posee aspectos propios, entretanto, comparten elementos que son recogidos por la visión del Sumak Kawsay que busca reestructurar la vida y las relaciones entre los seres humanos y la naturaleza, así como las acciones de resistencia de estos pueblos.
} 
De acuerdo con Carlos Viteri Gualinga (2002), político y uno de los primeros intelectuales indígenas a tratar del concepto, precisamente desde el Pueblo Originario de Sarayaku, señala que en la filosofía de los pueblos kichwas amazónicos no existen las dicotomías occidentales de desarrollo y subdesarrollo, tampoco los conceptos de riqueza y pobreza asociados a la acumulación de bienes materiales. Resalta el carácter holístico de esta filosofía que asocia tanto las condiciones materiales, como las condiciones espirituales para la vida humana, construyendo lo que considera como el "buen vivir" y la "vida armónica" provenientes del allí káusay y del súmac káusai del mundo kichwa.

Por consiguiente, el Sumak Kawsay construido desde los pueblos indígenas está asociado al proyecto político y social que busca resaltar sus indigeneidades en la sociedad capitalista globalizada, rescatando sus diferencias en medio de los intentos de homogeneización impuestas por la globalización neoliberal. Es una herramienta que busca salvaguardar las formas de vida de estos pueblos a través de las voces y las resistencias que buscan recuperar la soberanía de la vida en la Amazonía por medio de la autonomía y las relaciones de equilibrio con la naturaleza (SECO PÉREZ, 2017).

Adicionalmente, puede ser considerado una herramienta de organización del pensamiento y de la acción, con base en la ancestralidad y sus cosmovisiones que apunta a la descolonización y al quiebre de las dicotomías entre los seres humanos y la naturaleza, entre otras. Resalta las resistencias de los pueblos amazónicos frente a las amenazas del desarrollo extractivista como el fundamento para su materialización, junto con el reconocimiento de la autodeterminación de los pueblos y nacionalidades indígenas para lograr la protección integral de sus territorios (SECO PÉREZ, 2017).

Desde el punto de vista decolonial, apunta a la importancia del proceso de desprendimiento que es necesario para comprender la sabiduría y el modo de vida de estos pueblos, desprendiéndose de la mirada colonial presente en el pensamiento que considera que la única forma de vida existente y válida es el modelo de organización social occidental. Así, se torna necesario el reconocimiento de la existencia y la validez de otras formas de vida (CASTRO MUNIZ; CÁRDENAS PIEDRAHÍTA, 2018).

Dichas formas de vida apuntan al pluriverso, asociado a la coexistencia de diversos mundos que buscan resistir a la globalización hegemónica neoliberal por medio de las luchas de los movimientos sociales, las cuales también pueden ser consideradas luchas ontológicas, buscando inserir nuevamente la diversidad existente en el mundo, ocultada por la construcción del mundo singular de acuerdo con el pensamiento eurocéntrico. Visibiliza otros modos de ser, ver, estar y conocer el mundo, como las ontologías políticas relacionales que caracterizan las cosmovisiones y los sistemas de vida ancestrales de los pueblos y nacionalidades indígenas del país. Los modelos de visión de mundo relacionales de los pueblos indígenas consideran la existencia de diversos mundos interconectados, resaltando las conexiones existentes entre el mundo de los seres humanos y el mundo natural y espiritual (ESCOBAR, 2018).

Precisamente, conforme menciona José Gualinga (2017), desde el Pueblo Originario de Sarayaku, el Sumak Kawsay está estrechamente relacionado con la concepción del Kawsak Sacha, la 'selva viviente'. Este último concepto señala la vida, la energía, la sabiduría y la colectividad presentes en la selva. Considera que son fuentes para la existencia de los propios seres humanos, espacios llenos de riquezas y biodiversidad. Así, todo lo que compone el Kawsak Sacha está interrelacionado, incluso la vida de los antepasados y las vidas actuales están intrínsicamente asociadas al entorno natural. De esta manera, la destrucción de la 'selva viviente' es una amenaza a la vida de todos los seres.

Resalta los fundamentos importantes de la propuesta de reconocimiento de la selva como "selva viviente". En este sentido, plantea la necesidad de avanzar hacia la protección de la naturaleza, tanto a nivel nacional, como internacional, ya que, pese que Ecuador reconozca la naturaleza como sujeto de derecho, siguen los avances extractivistas ${ }^{10}$, especialmente la minería y las petroleras, apoyados por el propio Estado, afectando la vida, la cultura y los territorios de los pueblos amazónicos (GUALINGA, 2017).

\footnotetext{
${ }^{10}$ Larrea Maldonado, Bravo e Saénz (2017) resalta la ampliación de la frontera petrolera en el sur de la Amazonía, con la licitación de la XI Ronda petrolera y la explotación del Parque Nacional Yasuní, con dos bloques, el ITT y el bloque 31, a partir de 2013. La ampliación de la frontera petrolera sigue hasta la actualidad, a través de la subasta de diversos bloques petroleros por parte del Estado ecuatoriano.
} 
Así, la propuesta del Pueblo Originario de Sarayaku apunta al reconocimiento de la "selva viviente" como categoría jurídica que amplíe la protección de los territorios indígenas, transcendiendo las fronteras de Ecuador, de forma a transformar estos territorios en zonas libres de petróleo y minería, permitiendo la consolidación de los valores del Sumak Kawsay, es decir, permitiendo la autodeterminación y la ejecución de planes de desarrollo propios de las comunidades (GUALINGA, 2017).

Añade la necesidad de implantar un nuevo modelo de valores y de riquezas para el Sumak Kawsay a través de la construcción de planes de vida. Apunta a los objetivos del plan de construcción de la categoría de "selva viviente", buscando generar un modelo de desarrollo alternativo, resaltando las potencialidades científicas, culturales y tecnológicas propiciadas por la gran biodiversidad presente en la Amazonía. En este sentido, resalta la importancia de la administración propia de la biodiversidad de la región, juntamente con la manutención del territorio y de los ecosistemas preservados, libres de contaminación, especialmente petrolera. Considera que la propuesta de construcción de la categoría de "selva viviente" es una propuesta que posee carácter global, apunta a transformaciones a escala global, preservando los territorios de los pueblos originarios de todo el planeta, contribuyendo a la consolidación de la naturaleza como sujeto de derechos también en el ámbito global (GUALINGA, 2017).

Dicha propuesta está amparada por instrumentos legales, tanto nacionales, como internacionales. En el ámbito interno, se resalta la Constitución de 2008 de Ecuador que reconoce la plurinacionalidad, la interculturalidad y la naturaleza como sujeto de derecho; reconoce la naturaleza como el lugar en que se produce, se reproduce y se realiza la vida, en que todos pueden exigir el respeto a los derechos de la naturaleza; también reconoce los derechos colectivos de los pueblos y nacionalidades indígenas, como el derecho a la identidad propia, a la conservación de sus territorios, así como la consulta previa, libre e informada y la participación en las decisiones que involucren sus territorios; el derecho a la educación intercultural bilingüe; el derecho a vivir en un ambiente sano y ecológicamente equilibrado, que garantice el buen vivir. En el ámbito externo, está amparada por el Convenio 169 de la OIT que asegura el derecho a la protección de los territorios de los pueblos indígenas, que debe ser garantizado por los Estados; así como la Declaración de las Naciones Unidas sobre los Derechos de los Pueblos Indígenas de 2007, que, pese no ser vinculante, genera aportes para los debates ambientales y para las jurisprudencias a nivel internacional, como las de la Corte Interamericana de Derechos Humanos (SANTI; GHIROTTO SANTOS, 2020).

El artículo académico escrito por Daniel Santi, coordinador general de la propuesta del Kawsak Sacha, integrante del propio Pueblo Originario de Sarayaku, y la antropóloga brasileña Marina Ghirotto Santos, resalta la necesidad de proceder con el diálogo de saberes de carácter intercultural entre las concepciones occidentales, y las concepciones del mundo amazónico, que denominan de concepciones runas, que en kichwa significa "seres humanos" (SANTI; GHIROTTO SANTOS, 2020).

Ellos consideran que Sarayaku propone la construcción de una nueva categoría de conservación en territorios indígenas, ${ }^{11}$ teniendo en cuenta que aún no se ha garantizado la manutención de sus sistemas propios de vida, ni la autonomía sobre la totalidad del territorio, dado que los recursos naturales que se encuentran en el subsuelo, como el petróleo, siguen en manos del Estado. Estos planteamientos están asociados a la larga trayectoria de luchas y resistencias a las actividades extractivistas y a la defensa de sus territorios, también vinculado con la capacidad de la comunidad en generar categorías y propuestas propias, presentadas tanto al Estado, como a las organizaciones internacionales, como es el caso de las Naciones Unidas (SANTI; GHIROTTO SANTOS, 2020). Estas categorías están asociadas a las formas de "re-existencias" propuestas por Catherine Walsh (2017).

Hidalgo-Capitán y Cubillo-Guevara (2019) vinculan con las históricas presiones realizadas por el movimiento indígena amazónico sobre los reclamos territoriales, buscando negociar con el Estado ecuatoriano la ampliación de sus derechos. Así, buscan obtener el control del territorio, desde su superficie, impidiendo la entrada de colonos; también buscan el control del espacio aéreo, evitando la entrada de las petroleras en sus territorios, teniendo en cuenta la entrada de la compañía petrolera CGC, a través de helicópteros; y, so-

\footnotetext{
${ }^{11}$ Considera que esta categoría de conservación puede ser una alternativa a las categorías de conservación de carácter occidental, vinculadas al mercado, especialmente al mercado de carbonos que sigue mercantilizando la naturaleza y no soluciona los problemas de la explotación de recursos naturales a nivel global (SANTI; GHIROTTO SANTOS, 2020).
} 


\section{Debate}

bre todo, buscan el control del subsuelo con sus recursos naturales. Así, plantean la concepción del territorio como un elemento integral, conteniendo estas tres dimensiones: la superficie, el espacio aéreo y el subsuelo, de acuerdo con sus cosmovisiones, buscando garantizar la preservación territorial en toda su integralidad (HIDALGO-CAPITÁN; CUBILLO-GUEVARA, 2019).

La propuesta ha sido presentada en espacios nacionales e internacionales, especialmente en las últimas Conferencias de las Partes, las COP, realizadas en el marco de las reuniones y debates de las Naciones Unidas sobre el cambio climático. Apoyada en su propia concepción de vida, naturaleza y cosmovisión espiritual, busca ser una alternativa al modelo de conservación del medio ambiente y de desarrollo como forma de combatir el calentamiento global, contribuyendo a la internacionalización de la comunidad, así como de sus pensamientos (ARCOS HERVA, 2016).

Está asociada a lo que proponen varios intelectuales, como Rafael Bautista (2019), quien apunta a la necesidad de ocupar formas más racionales de producción, como las formas ancestrales de la región, atendiendo, primeramente, a las necesidades de la propia región, antes que del centro del sistema internacional. Teniendo en cuenta que los recursos de la naturaleza no son infinitos, estas propuestas no serían solamente un slogan, sino que la apuntan a la percepción de que es necesario lograr una relación de equilibrio entre la sociedad en general y la naturaleza, dado que la vida humana depende de la naturaleza. Son horizontes de sentido que pueden contribuir a la construcción de otras racionalidades económicas, proponiendo otras formas de relaciones entre los seres humanos y la naturaleza con proyección global.

\section{CONSIDERACIONES FINALES}

A través del análisis del caso del Pueblo de Originario de Sarayaku, de sus resistencias y "re-existencias", se ha tratado de visibilizar otros papeles que pueden ser ocupados por la región amazónica, que además de ser rica en biodiversidad y recursos naturales, es también un espacio de disputa de significados y generación de conocimientos propios en que se sobresalen las prácticas llevadas a cabo por otros actores, como los pueblos y nacionalidades indígenas, con gran capacidad de agencia política para visibilizar postulados que permiten considerar la naturaleza y otros seres como entidades dotadas de vida, racionalidad y capacidad política, transitando hacía el pluriverso al resaltar la existencia de otros mundos.

Precisamente, el Pueblo Originario de Sarayaku nos invita a ver el pluriverso a través de la lucha llevada a cabo contra las transnacionales petroleras y el Estado ecuatoriano, proponiendo alternativas a la globalización hegemónica por medio de propuestas de globalización contrahegemónica que evidencian la existencia de otros mundos, como es el caso del Kawsak Sacha, la "selva viviente", y el Sumak Kawsay, el buen vivir y la vida en plenitud, con posibilidad de trascendencia global, justamente desde sus cosmovisiones ancestrales. Su accionar evidencia la resistencia y la "re-existencia" al proponer otras concepciones.

El Sumak Kawsay ha sido integrado a la Constitución ecuatoriana, fundamentado en las luchas históricas del movimiento indígena del país, con la participación destacada de los líderes provenientes del Pueblo Originario Kichwa de Sarayaku. Entretanto, es importante mencionar que la introducción de algunas de sus propuestas, y la consiguiente construcción formal del Estado plurinacional, no ha significado la verdadera emancipación de los pueblos y nacionalidades indígenas del país, sino que ha sido un punto importante en la continuidad de sus luchas históricas. Ahora buscan la aplicación efectiva de estos conceptos, así como la construcción de otros, como el Kawsak Sacha, la "selva viviente", a ser transformada en derechos, contribuyendo a resguardar los derechos de los seres humanos, los runas, y los derechos de la naturaleza. Así, se pone de relieve la importancia de las acciones políticas y las propuestas epistémicas de este sector que contribuyen a los procesos de descolonización en los más distintos ámbitos, a través de las luchas, resistencias y "re-existencias" políticas, sociales, epistemológicas y ontológicas, tan necesarias frente a las constantes crisis del modelo de desarrollo hegemónico que enfrentamos.

\section{REFERENCIAS}

ACOSTA, A. Extractivismo y Neoextractivismo: dos Caras de la Misma Maldición. In: LANG, M.; GUDYNAS, E. (ed.). Más Allá del Desarrollo. Abya Yala: Universidad Politécnica Salesiana: Fundación Rosa Luxemburg, 2011. p. 83-120.

ACOSTA, A. Amazonia: Violencias, Resistencias, Propuestas. Revista Crítica de Ciências Sociais, 107, p. 39-62, 2015. Disponible en: Https://Doi.Org/10.4000/Rccs.6004. 
ARCOS HERVA, V. El Papel de las Redes Transnacionales de Defensa de los Derechos Humanos en el Conflicto Socioambiental Producido por la Explotación Petrolera en Sarayaku. 2016. Tesis (Maestría En Relaciones Internacionales con Mención en Negociación y Cooperación Internacional) - Flacso Ecuador, 2016. Disponible en: Http://Repositorio.Flacsoandes.Edu.Ec/Bitstream/10469/8932/1/Tflacso-2016vah.Pdf.

BAUTISTA, S. R. El Tablero del Siglo XXI: Geopolitica Des-Colonial de un Nuevo Orden Post-Occidental. [S.I.]: Yo Soy Si Tú Eres Ediciones ; El Taller De La Descolonización, 2019.

BERNAL-MEZA, R. Contemporary Latin American thinking on International Relations: Theoretical, conceptual and methodological contributions. Revista Brasileira de Política Internacional, v. 59, n. 1, p. 1-32, 2016.

BERRíOS, C.; CUEVAS, V. El Petróleo y La Resistencia Indígena en Ecuador. Desafíos a la Políticas Neo-Extractivistas en América Latina. In: Saltar La Barrera: Crisis Socio-Ambiental, Resistencias Populares y Construcción Alternativas Latinoamericanas Al Neoliberalismo. Instituto de Ciencias Alejandro Lipschutz, 2014. p. 109-126.

CARCELÉN, J. Estado de Cumplimiento de Medidas Reparativas: Caso Sarayaku. 2017. Trabajo de Grado (Relaciones Internacionales) - Universidad Internacional Del Ecuador. Disponible en: Http://Repositorio.Uide.Edu.Ec/Handle/37000/2453.

CASTRO MUNIZ, M. L.; CÁRDENAS PIEDRAHÍTA, A. M. Geo-Grafías Decoloniales y el Pensamiento Femenino Indígena. Tejiendo y Modelando Resistencias y Re-Existencias en la Amazonía Ecuatoriana. In: CANALES TAPIA, P.; VARGAS, S. (ed.). Pensamiento Indígena en Nuestramérica: Debates y Propuestas en la Mesa de Hoy. Ariadna Ediciones, 2018. p. 101-158.

CRESPO, J. M. Sistematización Conceptual del Buen Vivir: del Sumak Kawsay al Buen Vivir. In: LARREA MALDONADO, C.; GREENE LÓPEZ, N. (ed.). Buen Vivir como Alternativa al Desarrollo: una Construcción Interdisciplinaria y Participativa. Equador: Universidad Andina Simon Bolivar, 2017. p. 12-32. Disponible en: Http://Repositorio.Uasb.Edu.Ec/Handle/10644/5964.

ESCOBAR, A. Designs for the Pluriverse: Radical Interdependence, Autonomy, and the Making of Worlds. Durham, Carolina do Norte, EUA: Duke University Press, 2018.

GUALINGA, J. Reconocimiento de Kawsak Sacha - Selva Viviente - Como Nueva Categoría de Protección a los Territorios Indígenas en la Amazonía Centro - Sur. In: LARREA MALDONADO, C.; GREENE LÓPEZ, N. (ed.). Buen Vivir como Alternativa al Desarrollo: una Construcción Interdisciplinaria y Participativa, 2017. p. 106-112. Ecuador: Universidad Andina Simon Bolivar, 2017. Disponible en: Http://Repositorio.Uasb.Edu.Ec/Handle/10644/5964.

GUDYNAS, E. Extractivismos: Ecología, Economía y Política de un Modo de Entender el Desarrollo y la Naturaleza. Cochabamba, Bolívia: Cedib - Centro de Documentación e Información Bolivia, 2015.

HIDALGO-CAPITÁN, L.; CUBILlO-GUEVARA, A. P. El Origen del Buen Vivir: el Plan Amazanga de la Opip. Huelva, Guatemala: Ediciones Bonanza, 2019.

LARREA MALDONADO, C.; BRAVO, A. L.; SAÉNZ, M. El Neo-Extractivismo en el Ecuador: Crisis y Alternativas. In: GREENE LÓPEZ, N. (ed.). Buen Vivir Como Alternativa al Desarrollo: una Construcción Interdisciplinaria y Participativa. Ecuador: Universidad Andina Simon Bolivar, 2017. p. 136-154. Disponible en: Http://Repositorio.Uasb.Edu.Ec/Handle/10644/5964.

LLASAG, R. Constitucionalismo Plurinacional En Ecuador Y Bolivia A Partir De Los Sistemas De Vida De Los Pueblos Indígenas. 2017. Tesis (Doctorado en Poscolonialismo y Ciudadanía Global) - Universidad de Coímbra. Disponible en: Http://Hdl.Handle. Net/10316/36285.

MELO, M. El Caso Sarayaku y los Derechos Humanos: ¿Por Qué Sarayaku Constituye un Caso Emblemático de Exigibilidad de Derechos a Nivel Internacional? In: Pueblos en Lucha: Raposa Sierra del Sol - Camisea - Awas Tingni - Sarayaku. Memoria del Foro: Casos Emblemáticos de Defensa de Derechos Indígenas. 2004. p. 42-54. Disponible en: Http://Bibliotecavirtual.Clacso. Org.Ar/Ar/Libros/Derecho/Libro3.Pdf.

PUEBLO originario Kichwa de Sarayaku. Corte Interamericana de Derechos Humanos: Caso Pueblo Indígena Kichwa de Sarayaku Vs. Ecuador - Caso n. 12.465, 2009. Http://Www.Corteidh.Or.Cr/Docs/Casos/Sarayaku/Esap.Pdf.

SANTI, D.; GHIROTTO SANTOS, M. Kawsak Sacha-Selva Viviente: Perspectivas Runas sobre Conservación. Vivência: Revista de Antropologia, 1(53), 2020. Disponible en: Https://Doi.Org/10.21680/2238-6009.2019v1n53id20911.

SECO PÉREZ, C. Sumak Kawsay: ¿Concepto Sagrado o Instrumento? Caminando la Plenitud: Sumak Kawsay desde las Voces en Resistencia de la Amazonía Ecuatoriana. In: C. LARREA MALDONADO, C.; GREENE LÓPEZ, N. (ed.), Buen Vivir Como Alternativa al Desarrollo: una Construcción Interdisciplinaria y Participativa, 2017. p. 75-97. Ecuador: Universidad Andina Simon Bolivar. Disponible en: Http://Repositorio.Uasb.Edu.Ec/Handle/10644/5964.

SIMBAÑA, F. El Sumak Kawsay Como Proyecto Político. In: LANG, M.; GUDYNAS, E. (ed.). Más Allá Del Desarrollo. Abya Yala: Universidad Politécnica Salesiana; Fundación Rosa Luxemburg, 2011. p. 219-226.

VITERI, F. La Lucha de Sarayaku. In: Pueblos en Lucha: Raposa Sierra Del Sol - Camisea - Awas Tingni - Sarayaku. Memoria del Foro: Casos Emblemáticos de Defensa de Derechos Indígenas. 2004. p. 19-23. Disponible en: Http://Bibliotecavirtual.Clacso. Org.Ar/Ar/Libros/Derecho/Libro3.Pdf.

VITERI GUALINGA, C. Visión Indígena del Desarrollo en la Amazonía. Polis - Revista Latinoamericana, 3, 2002. Disponible en: $\mathrm{Https://Polis.Ulagos.Cl/Index.Php/Polis/Article/View/183/275.}$

WALSH, C. E. (2017). Gritos, Grietas Y Siembras De Vida: Entretejeres De Lo Pedagógico Y Lo Decolonial. En C. Del P. Cuevas Marín (Ed.), Pedagogías Decoloniales: Prácticas Insurgentes De Resistir, (Re)Existir Y (Re)Vivir (Pp. 17-48). Abya Yala. 